\title{
ASSESSMENT OF GOOD HYGIENIC PRACTICES AMONG FOOD PROCESSORS IN SMALL FOOD BUSINESSES IN BARISAL CITY CORPORATION OF BANGLADESH
}

\author{
A. K. Paul ${ }^{1 *}$, M. M. $\operatorname{Riad}^{2}$ and A Chandra ${ }^{3}$ \\ ${ }^{1}$ Department of Medicine, Surgery and Obstetrics, ${ }^{2}$ Department of Basic Science, Faculty of Animal science and \\ Veterinary Medicine, Patuakhali Science and Technology University, Barisal-8210, Bangladesh; ${ }^{3}$ Department of \\ Livestock Services, Ministry of Fisheries and Livestock, Dhaka, Bangladesh
}

\begin{abstract}
The food safety is the alarming issue for the global heath. The aim of this study is to assess the awareness on GHP of food processors, working in different food businesses in Barisal City Corporation area of Bangladesh. A questionnaire was used which includes the use of cutting tool for food, use of gloves during food processing, knowledge about zoonotic diseases, work with sickness, aware during food serving, shower before work, personal hygiene, separate working dress and aware about customer health. 93 food processors were interviewed during the period from January to March 2015. In this study, we found that $89.2 \%$ food processor were used boti for cutting the food which was significantly higher than that of use knife $(10.8 \%) .71 \%$ food processor were not used hand gloves during cutting and processing the food which was significantly higher than that of use gloves $(29 \%)$. We also found out that $35.5 \%$ were processors were worked with sickness where as $54.8 \%$ worker has no knowledge about the food borne disease transmission which was significantly higher than that of knowledge about that (45.2\%). $67.7 \%$ were worker not use any separate dress during their work and $28 \%$ processor did not aware about the customer health hygiene. $91.4 \%$ worker was concern about their personnel cleanliness such as cutting nail, use of shop after toilet etc. However, the food processor awareness during food processing and serving to the people is essential for public health significance. Therefore, from this study, it may be recommended that the proper training of food processors is necessary to protect consumers' health.
\end{abstract}

Keywords: Awareness, Barisal City Corporation, food processor, food shop, public health

\section{INTRODUCTION}

Food hygiene and food safety is an alarming issue for public health not only in Bangladesh but also all over the world. Food is a significant reason for the huge number of disease transmission in the entire world. Bangladesh, a third world developing country of South Asia, is not an exception in this case. Inadequate diets and intake of adulterated foods are responsible for the malnutrition of $60 \%$ of the people of Bangladesh (Ali, 1984). The Institute of Public Health (IPH) in Dhaka and the World Health Organization (WHO) in their joint study on food adulteration tested 52 street vendors and found that, all of the vendors' food samples (100\%) were contaminated with different types of disease breeding microorganisms (Badrie et al., 2006). Unhygienic practices in food handling become a common phenomenon in the Bangladesh food industry. Countless restaurants, fast food outlets are cooking, baking and processing foods in extremely unhealthy environments. In another report, it was revealed that in Bangladesh at least 501 people visits hospital every day for diarrhoeal diseases that are related to food safety (Ali, 2013). This long diarrhoeal disease problem, related to food safety, persists and it has been a significant cause of malnutrition in Bangladesh for the last couple of decades (DGHS, 2012).

There are some reasons such as lack of consumer and food processor education is liable for food safety problems in Bangladesh (Huda et al, 2009). However, Good Hygiene Practices (GHP) of the food processor may overcome the food safety problem. GHPs are the set of requirements to prevent contamination of food in order to provide safe food to the consumers. Therefore, the aim of this study is to assessment the awareness on GHP of food processors, working in different food businesses in Barisal City Corporation area of Bangladesh.

\section{MATERIALS AND METHOD}

\section{Study area}

This was conducted at the in Barisal City Corporation (BCC) area of Bangladesh.

*Corresponding e-mail address: akpau12008@gmail.com 


\section{A. K. Paul and others}

\section{Data collection}

The study was conducted during the period from January to March 2015. An interview schedule which was included the use of cutting tool for food cutting, use of gloves during food processing, knowledge about zoonotic diseases, work with sickness, aware during food serving, shower before work, personal hygiene, aware about customer health and separated working dress. A total of 93 food processors were interviewed randomly from different food shop during the period.

\section{Statistical analysis}

The collected data was entered in the Microsoft Excel 2010 and were coded, scored, compiled, tabulated. Data had been analyzed by proportion test (Z- test) using SPSS $^{\circledR}$ (version 20.0).

\section{RESULTS AND DISCUSSIONS}

The study was conducted at the in Barisal City Corporation (BCC) area of Bangladesh during the period from January to March 2015. 93 food processors were interviewed by using a pre-test questionnaire which was included the use of cutting tool for food, use of gloves during food processing, knowledge about zoonotic diseases, work with sickness, aware during food serving, shower before work, personal hygiene, separate working dress and aware about customer health.

\section{Using tools during food processing}

In this study, we found that $89.2 \%$ food processors were using boti (locally made specialized knife) and $10.8 \%$ were knife (Figure 1). Boti was used significantly higher than that of knife. In case of wearing hand gloves during food processing or cutting, we found that most (71\%) of the food processor did not use gloves whereas only few processor $(29 \%)$ were used (Figure 2). The cutting tools may act as a cross-contamination of food. Zymberaj et al. (2006) stated in their GFH manual that cross-contamination is one of the most common causes of food poisoning which happens when harmful bacteria distributed on food by the device, hands, face or other food. Washing the boti and keep it clean is more hazardous than that of knife due to its structural differences. On the other hand, a lot of food borne disease transmitted through the open hand (Figure 3). It is reported that most of the diarrhoeal patients in Bangladesh are become infected due to unhygienic hand (Motarjemi et al., 1993). According to the guideline of Codex Alimentarius Commission (CAC, 1999), it is suggested that the proper washing of hand and use of hand gloves will reduces the chance of food contamination.

\section{Knowledge about public health hygiene}

In the present study, it was demonstrated that most of the food processor had no knowledge regarding the zoonotic disease (Table 1). However, we found that $72 \%$ food processors were aware about public health hygiene and $68.2 \%$ had awareness for customer food. Ali (2013) reported that most of the food processor or shop keepers are aware about the public food hygiene but they have the tendency to violate the roles due to regulatory reasons. Various socio-economic, cultural, and regulatory reasons may be liable for these food safety problems in Bangladesh, such as lack of consumer education (Huda et al., 2009), product price (Hossain et al., 2008), multiplicity of laws, lack of coordination (Ali, 1984), lack of adequate punishments, judicial restraint (Andaleeb and Ali, 2009). Therefore, the strong commitment and regulations of government may control these problems.

\section{Personal cleanliness during food processing}

In this study, it has been explored that food processors suffering with any disease for last two weeks were $23.7 \%$ whereas $35.5 \%$ were working with sickness. The percentage of food processor did not shower before working, did not cut nail weekly and didn't use separate dress were 31.2, 8.6 and $67.7 \%$, respectively. According to the guideline of CAC (1999 revised at 2003), people who do not maintain an appropriate degree of personal cleanliness, who have certain illnesses or conditions or who behave inappropriately, can contaminate food and transmit illness to consumers. Food handlers should maintain a high degree of personal cleanliness and, where appropriate, wear suitable protective clothing, head covering, and footwear. Cuts and wounds, where personnel are permitted to continue working, should be covered by suitable waterproof dressings (Zymberaj et al., 2006; CAC, 1999). It is demonstrated that food handlers' attitude have positive and significant relationships with safe food handling. It is essential for food handling certification program, which reveal behavioural change for a better quality training (Aziz and Dahan, 2013). 
Good Hygienic Practices among food processors

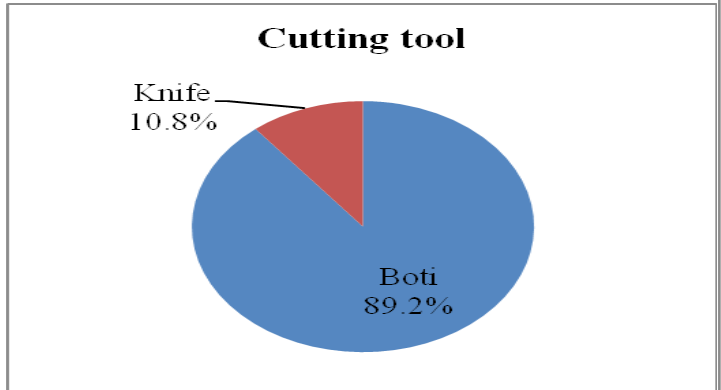

Figure 1. Use of cutting tools during food processing

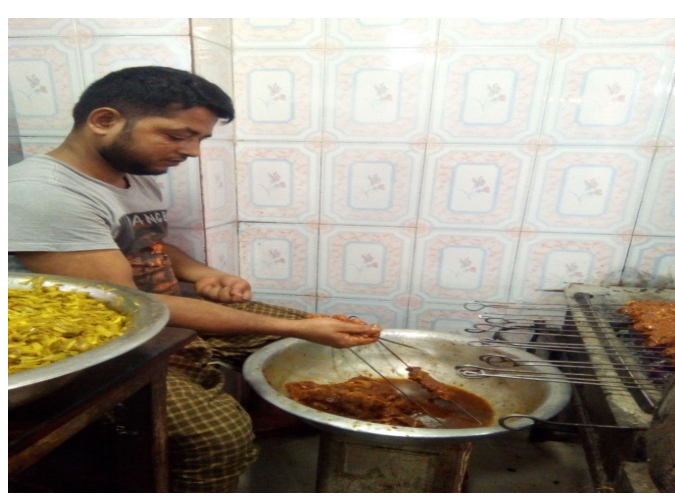

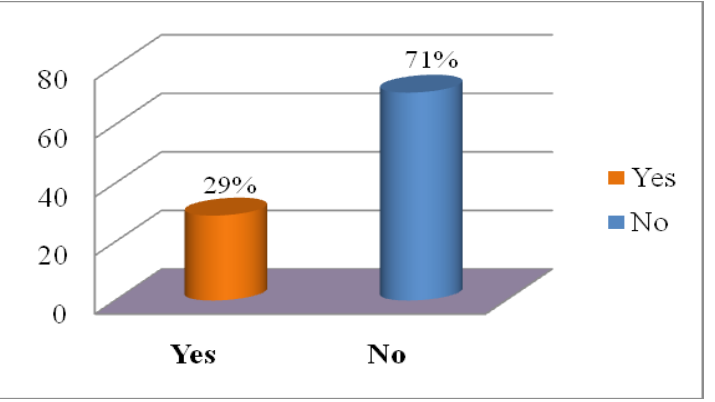

Figure 2. Use of hand Gloves during prepare food

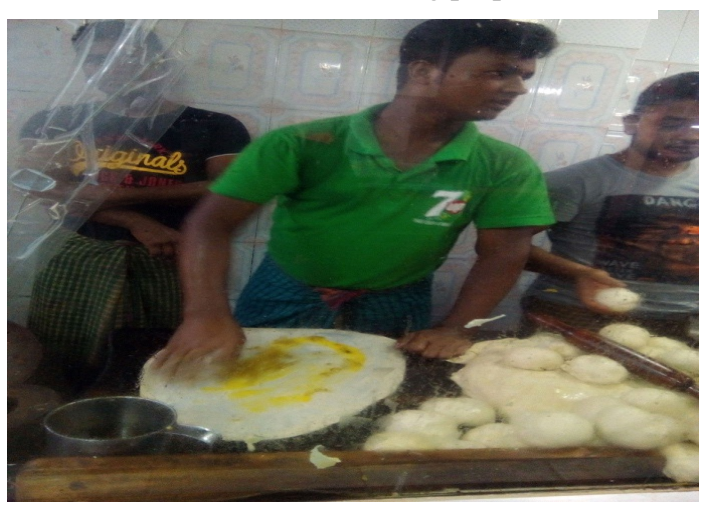

Figure 3. Food processors handling food hygiene

Table 1. Knowledge about public health hygiene

\begin{tabular}{|c|c|c|c|c|}
\hline Variables & & Frequency & Percent $(\%)$ & $\mathrm{P}$ value \\
\hline \multirow{2}{*}{ Transmission of disease from food to human } & Yes & 42 & 45.2 & \multirow{2}{*}{0.175} \\
\hline & No & 51 & 54.8 & \\
\hline \multirow{2}{*}{ Awareness about public health hygiene } & Yes & 67 & 72 & \multirow{2}{*}{0.000} \\
\hline & No & 26 & 28 & \\
\hline \multirow{2}{*}{ Awareness about customer food } & Yes & 64 & 68.8 & \multirow{2}{*}{0.000} \\
\hline & No & 29 & 31.2 & \\
\hline
\end{tabular}

Table 2. Personal cleanliness during food processing

\begin{tabular}{|c|c|c|c|c|}
\hline Variables & & Frequency & Percent $(\%)$ & $\mathrm{P}$ value \\
\hline \multirow[b]{2}{*}{ Whether suffering from any disease for last two weeks } & Yes & 22 & 23.7 & \multirow[b]{2}{*}{0.000} \\
\hline & No & 71 & 76.3 & \\
\hline \multirow{2}{*}{ Working with sickness } & Yes & 33 & 35.5 & \multirow{2}{*}{0.997} \\
\hline & No & 60 & 64.5 & \\
\hline \multirow{2}{*}{ Shower before working } & Yes & 64 & 68.8 & \multirow{2}{*}{0.000} \\
\hline & No & 29 & 31.2 & \\
\hline \multirow{2}{*}{ Cutting nail weekly } & Yes & 85 & 91.4 & 0.000 \\
\hline & No & 08 & 8.6 & \\
\hline \multirow{2}{*}{ Use of separate Working Dress } & Yes & 30 & 32.3 & \multirow{2}{*}{0.000} \\
\hline & No & 63 & 67.7 & \\
\hline
\end{tabular}




\section{A. K. Paul and others}

\section{CONCLUSIONS}

Food safety is a sensitive area which may affect every human being directly and indirectly. The training of food processor is necessary. The government, different donor and private organization may play an important role to train up as well as certify them for doing the work of food processing. Regular monitoring, application of legislation and campaign for people awareness will combat the food hygiene and safety problem in Bangladesh. It might start implementation from the city corporation to the rural area.

\section{ACKNOWLEDGMENT}

The authors express their cordial gratefulness to the sixth semester's students of the Faculty of Animal Science and Veterinary Medicine, Patuakhali Science and Technology University, Patuakhali, Bangladesh for the data collection for this study.

\section{REFERENCES}

1. Ali ANMA (2013). Application of responsive regulation in the food safety regulations of Bangladesh. Journal of South Asian Studies 1: 01-09.

2. Ali ANMA (2013). Food safety and public health issues in Bangladesh: a regulatory. European Food and Feed Law Review 8: 31-40.

3. Ali QM (1984). Some aspects of consumer protection in Bangladesh. The Dhaka University Studies Part-C; 111 119.

4. Andaleeb Z and Ali ANMA (2009). The development of consumer protection law in Bangladesh: A critical comparative study. Independent Business Review 2: 131-143.

5. Aziza SAA and Dahan HM (2013). Food Handlers' attitude towards safe food handling in school canteens. Procedia of Social and Behavioral Science 105: 220-228.

6. Badrie N, De Leon SY and Talukder MRA (2006). Food adulteration management systems: Initiatives of Trinidad and Tobago, West Indies, Philippines and Bangladesh (paper presented at Caribbean Agro-Economics Society 26th West Indies Agricultural Economic Conference, Puerto Rico, July 2006) 85.

7. CAC (Codex Alimentarius Commission) (2003). The current version of the recommended international code of practice-general principles of food hygiene including annex on hazard analysis and critical control point (HACCP) system and guidelines for its application was adopted by the Codex Alimentarius Commission in 1997. Amendments regarding rinsing adopted in 1999. HACCP Guidelines were revised in 2003.

8. DGHS (Directorate General of Health Services) (2012). Communicable Diseases. Government of Bangladesh.

9. Hossain MM, Heinonen V and Islam KMZ (2008). Consumption of foods and foodstuffs processed with hazardous chemicals: A case study of Bangladesh. International Journal Consumer Studies 32: 588-595.

10 Huda SSM, Ahmed S, Muzaffar T and Ahmed JU (2009). An Enquiry into the perception on food quality among urban people: A case of Bangladesh. African Journal of Business Management 3: 227-232.

11. Motarjemi and Yasmine et al (1993). Contaminated weaning food: A Major risk factor for diarrhoea and associated malnutrition. Bulletin of the World Health Organization 71: 79-92.

12.Zymberaj I, Resyli P, Kolgeci K and Berisha G (2006). Manual good hygiene practices (GHP) for food business subjects.http://twinningvet-ks.eu/files/old\%20guides/RKS\%20Guide\%20to\%20GP\%20-\%20Restaurants $\% 20$ ENG.pdf. 